\title{
Left Superomedial Segment
}

National Cancer Institute

\section{Source}

National Cancer Institute. Left Superomedial Segment. NCI Thesaurus. Code C79734.

Couinaud segment IVa, corresponding to the medial segment of the left lobe of the liver, located superiorly. 